\title{
Laboratory testing of the Spiegelberg brain pressure monitor: a technical report
}

\author{
Marek Czosnyka, Zofia Czosnyka, John D Pickard
}

The UK Shunt

Evaluation Laboratory and Academic

Neurosurgical Unit, Addenbrooke's

Hospital, PO Box 167, Hills Road, Cambridge CB2 2QQ, UK

M Czosnyka

Z Czosnyka

J D Pickard

Correspondence to: Dr Marek Czosnyka, Academic Neurosurgical Unit, Addenbrooke's Hospital, Hills Road, PO BOX 167, Cambridge CB2 2QQ, UK. Fax +441223 216926; email MC141@ MEDSCHL.CAM.AC.UK

Received 18 April 1997 Accepted 10 June 1997

\begin{abstract}
Objectives-The Spiegelberg brain pressure monitor is a low cost intracranial pressure monitoring system that has been used clinically for some time, mainly in Germany. To provide a rigorous bench comparison of the Spiegelberg monitor with the Camino pressure monitor an evaluation programme has been carried out in the UK Shunt Evaluation Laboratory.

Design-Drift over 72 hours and with temperature, a frequency response, and the accuracy of measurement of both static and pulsatile pressures have been tested simultanously in Camino and Spiegelberg transducers using a computerised rig.

Results-Long term zero drift was less than $0.7 \mathrm{~mm} \mathrm{Hg}$ in both transducers. The Spiegelberg monitor showed no temperature drift whereas the Camino monitor had a drift of around $0.3 \mathrm{~mm} \mathrm{Hg} /{ }^{\circ} \mathrm{C}$. The Spiegelberg monitor underread mean pressures $<40 \mathrm{~mm} \mathrm{Hg}$ by $<1 \mathrm{~mm} \mathrm{Hg}$, but the error increased to $4.7 \mathrm{~mm} \mathrm{Hg}$ at 100 $\mathrm{mm} \mathrm{Hg}$. The frequency bandwidth of the Spiegelberg monitor was $4 \mathrm{~Hz}$ at a low pressure. Underreading of the amplitude increased with the mean pressure, with a delay of about $0.1 \mathrm{~s}$ in the detection of the peaks of pulse waveform.

Conclusion-The Spiegelberg transducer had excellent accuracy for static intracranial pressure measurement, but complex
\end{abstract}

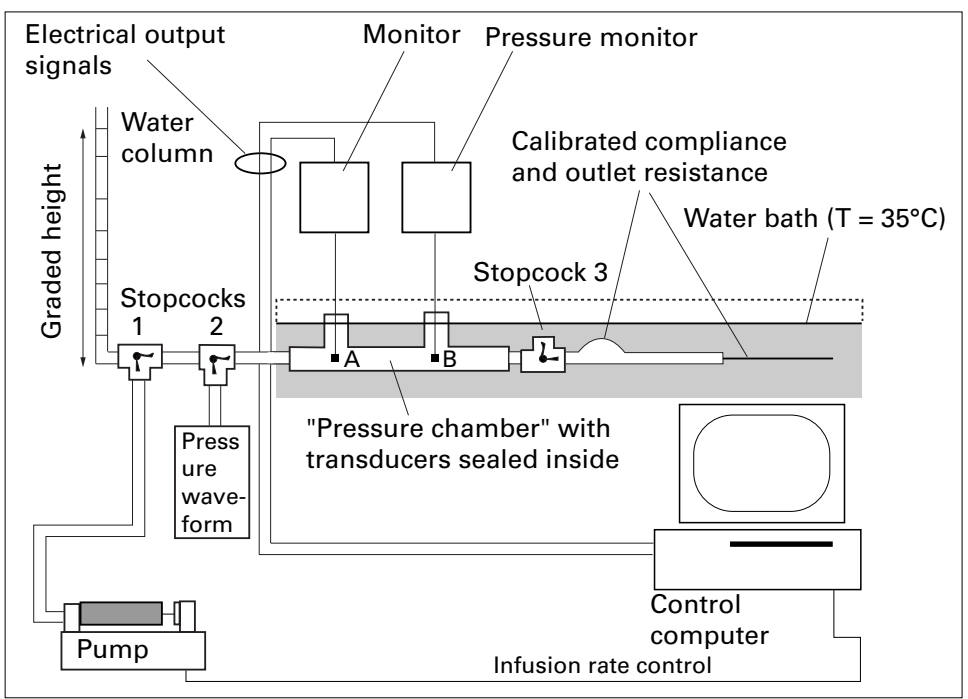

Figure 1 Schematic diagram of the testing rig. See description in the text. waveform analysis may be biased by its limited dynamic response.

\section{(F Neurol Neurosurg Psychiatry 1997;63:732-735)}

Keywords: pressure transducer; intracranial pressure; laboratory; evaluation

In the past decade more models of intraventricular or intraparenchymal microtransducers such as as Camino and Codman pressure sensors ${ }^{1}$ have become available. A low $\operatorname{cost}^{23}$ intracranial Spiegelberg brain pressure monitor for epidural pressure measurements has been used clinically for some time, mostly in Germany. The Spiegelberg transducer is constructed as an air pouch plastic disposable probe. It is much cheaper than contemporary intracranial pressure (ICP) microtransducers and it is now designed to measure intraventricular or intraparechymal pressure. The aim of this evaluation was to provide extensive bench testing to compare the Spiegelberg monitor with the Camino pressure monitor, previously evaluated in our laboratory. ${ }^{1}$ A long term ( 24 hours) and a temperature zero drift, frequency response characteristics, and the accuracy of measurement of static and pulsatile pressures were studied.

\section{Method}

Figure 1 shows the testing rig described. ${ }^{3}$

A Spiegelberg Probe 3 and Camino pressure transducer were sealed inside a chamber made from a $10 \mathrm{~cm}$ long section of soft polyethylene tube (15 $\mathrm{mm}$ diameter), having its own compliance of $0.1 \mathrm{ml} / \mathrm{mm} \mathrm{Hg}$. A stiff tubing (manometer line) was used as an input port for the water filled measurement chamber. A three way tap with Luer lock was connected at the output.

The chamber was submerged horizontally in a water bath with the temperature stabilised at $35^{\circ} \mathrm{C}$. Static pressure was produced by a water column in a graded vertical tube (1.5 m high). A pulsatile pressure waveform of fundamental frequency, controlled from the waveform generator, was applied using a pressure system calibrator (Biotek Instruments Inc, Winooski, VT, USA). Additionally, a fluid infusion at a computer controlled rate was performed to gradually increase the pressure inside the tubing. During the infusion the static pressure was cut off (using stopcock 1) and the outlet from the pressure chamber was connected (using stopcock 3) to a chamber with known compliance (around $1 \mathrm{ml} / \mathrm{mm} \mathrm{Hg}$ ) and resistance to fluid outflow ( $30 \mathrm{~mm} \mathrm{Hg} / \mathrm{ml} / \mathrm{min}$ ). 


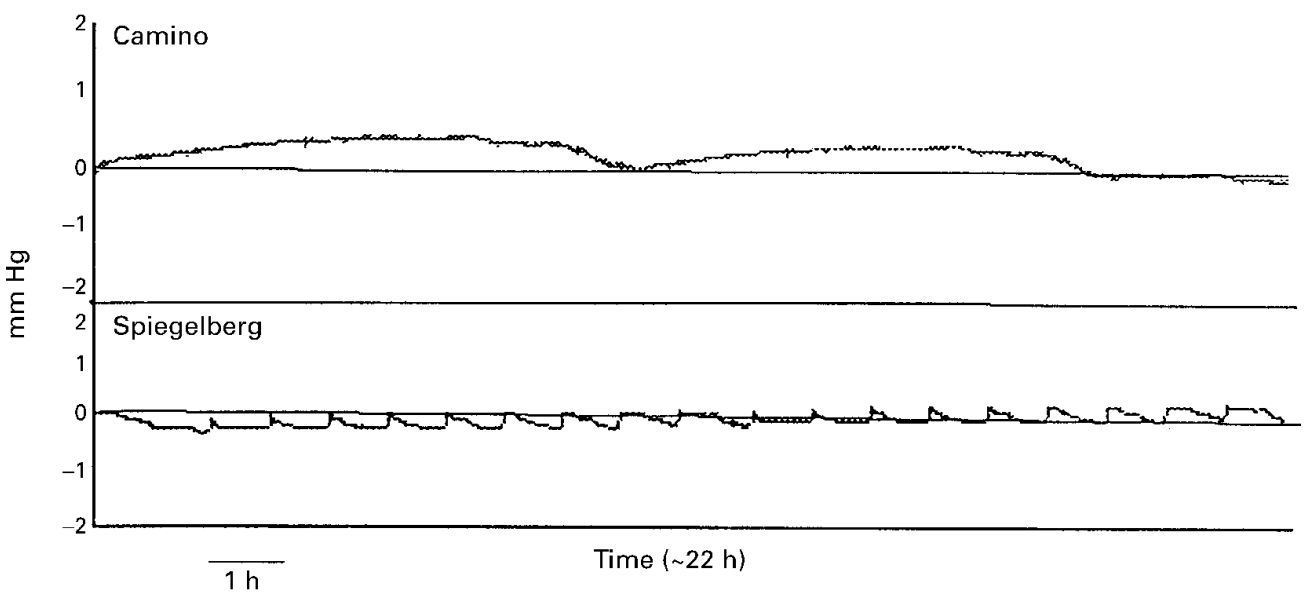

Figure 2 Example of the drift of Camino (upper) and Spiegelberg monitors (bottom) over 24 hours.

The Camino transducer was connected to the Camino pressure monitor V420 and the Spiegelberg Probe 3 was connected to the Spiegelberg brain pressure monitor. Their electrical outputs were connected to the computer system equipped with an analogue to digital converter (DT 2814, Data Translation, Marlboro, MA, USA).

Software for the analysis of pressure-flow relations in hydrocephalus shunts, which has been designed in house for the UK Shunt Evaluation Laboratory (MC and ZC; software is not available commercially) was used for on line data processing. Signals were sampled with a frequency of $100 \mathrm{~Hz}$. Digital spectral analysis was performed using a 256 point FFT algorithm. The amplitudes of the fundamental harmonics of periodic waveforms (amplitude and frequency) were calculated using a high precision interpolation algorithm. The mean values of the measured pressures were calculated as an average of 256 consecutive samples. The power of the higher harmonics were calculated as the averaged power spectra from 1.5 of the fundamental frequency to $50 \mathrm{~Hz}$. One minute average values of the calculated parameters from over 20 consecutive epochs were computed, displayed, and stored on hard disk. Data were than exported to a commercial statistical package (Statgraphic + , Manugistic, Rockville, MD, USA) for final calculations. Pressure waveforms were also recorded digitally on accessory computer for additional postprocessing.

Comparison of transducers $(1=$ better; $2=$ worse $)$

\begin{tabular}{lll}
\hline & Camino & Spiegelberg \\
\hline 24 hours zero drift & 1 & 1 \\
Temperature drift $\left(27^{\circ} \mathrm{C}-40^{\circ} \mathrm{C}\right)$ & 2 & 1 \\
Accuracy in static measurement & $1(<1 \mathrm{~mm} \mathrm{Hg} / 100 \mathrm{~mm} \mathrm{Hg})$ & $2(5 \mathrm{~mm} \mathrm{Hg} / 100 \mathrm{~mm} \mathrm{Hg})$ \\
Accuracy in measurement of pulse & $\star$ & Decreasing with mean \\
pressure & $\star$ & pressure increasing \\
Bandwidth & $\star$ & $4 \mathrm{~Hz}$ at $10 \mathrm{~mm} \mathrm{Hg}$ mean \\
& pressure \\
Pulse recording & Peak to peak amplitude \\
& & underestimated, delayed \\
& & $0.1 \mathrm{~s}$ \\
\hline
\end{tabular}

^These values were measured relative to the Camino monitor.

\section{Results}

ZERO DRIFT OVER 24 HOURS

The long term drift was measured in a water bath with temperature stabilised at $35^{\circ} \mathrm{C}$ for two different static pressures: 0 and $20 \mathrm{~mm} \mathrm{Hg}$. Transducers were calibrated and left for 24 hours. The water column was covered to prevent evaporation. The drift measured over three consecutive 24 hour periods was lower than $0.7 \mathrm{~mm} \mathrm{Hg}$ in both transducers, independent of static pressure. A specific, saw shaped trend (one hour period, amplitude lower than $0.3 \mathrm{~mm} \mathrm{Hg}$ ) was recorded from the Spiegelberg brain pressure monitor, as it is adjusted to zero automatically every hour (fig 2).

\section{TEMPERATURE DRIFT}

Temperature drift was measured as the water bath temperature was increased from $27^{\circ} \mathrm{C}$ to above $40^{\circ} \mathrm{C}$. Temperature was measured electronically using a precise electronic meter built in house (accuracy $>0.01^{\circ} \mathrm{C}$ ).

The measurement of the drift was repeated four times and the results were averaged.

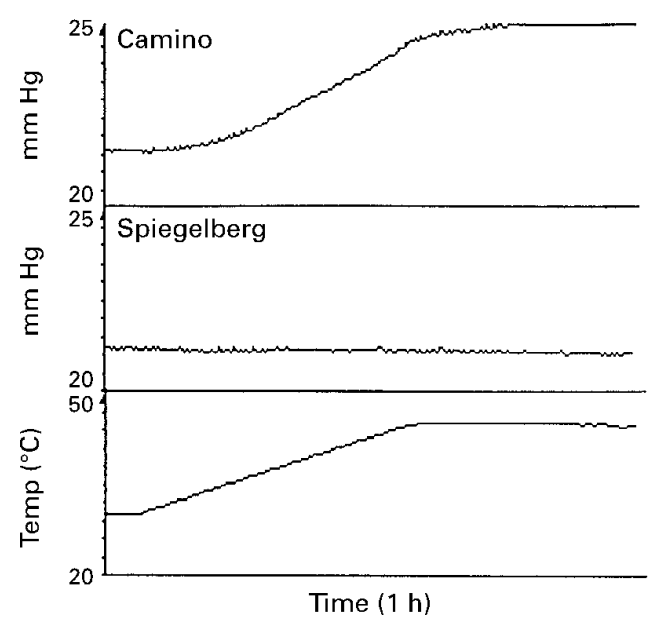

Figure 3 Drift recorded in Camino and Spiegelberg monitors during an increase in temperature from $27^{\circ} \mathrm{C}$ to $40^{\circ} \mathrm{C}$. 

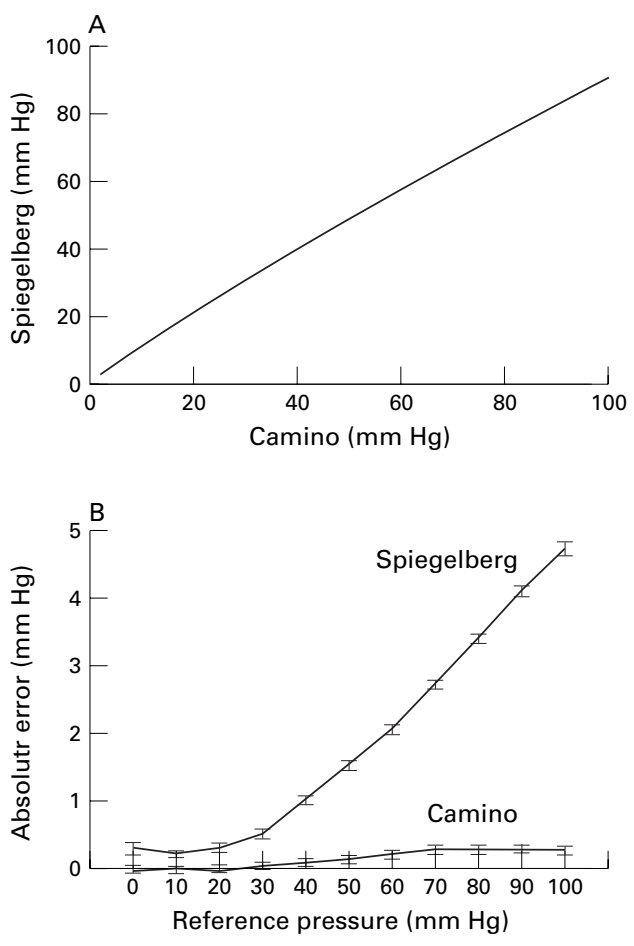

Figure 4 (A) Readings from the Spiegelberg transducer plotted against readings from the Camino transducer during ramp increase in pressure from 0 to $100 \mathrm{~mm} \mathrm{Hg}$ (over 20 min). (B) absolute error of the reading from the Spiegelberg and Camino transducers during a series (15) of stepwise decreases in the pressure by $10 \mathrm{~mm} \mathrm{Hg}$, from $100 \mathrm{~mm} \mathrm{Hg}$ to $0 \mathrm{~mm} \mathrm{Hg}$. Vertical bars indicate SEM.

The Camino monitor showed a drift of 0.27 $\mathrm{mm} \mathrm{Hg} /{ }^{\circ} \mathrm{C}$. The Spiegelberg pressure monitor did not show any significant drift (fig 3).

STATIC ACCURACY

During infusion of a rate increasing slowly the static pressures recorded by two transducers (increasing at a rate of $4 \mathrm{~mm} \mathrm{Hg} / \mathrm{min}$ ) were compared. Readings from the Spiegelberg transducer plotted against readings from the Camino transducer showed a minimally distorted, repeatable line $(\mathrm{R}=0.999$, gradient 0.92 fig $4 \mathrm{~A}$ ).

The reference static pressure was produced by changing the height of the water column (fig 4B). Water flowed out through the opened stopcock 3 (fig 1), thereby gradually decreasing the static pressure in intervals of $10 \mathrm{~mm} \mathrm{Hg}$. The procedure was repeated 15 times. The accuracy of the static measurement was expressed as the absolute difference between the reference and the measured pressures, plotted against the reference pressure-see below (mean value (SEM)).

The Spiegelberg transducer had static error $<1 \mathrm{~mm} \mathrm{Hg}$ up to the reference pressure of 40 $\mathrm{mm} \mathrm{Hg}$ (fig 5). Beyond this pressure the absolute error increased to $5 \mathrm{~mm} \mathrm{Hg}$ at $100 \mathrm{~mm}$ $\mathrm{Hg}$. The Camino static error was $<0.7 \mathrm{~mm} \mathrm{Hg}$.

FREQUENCY RESPONSE

Only the relative changes in the readings of the fundamental amplitude versus the frequency of the sine pressure waveform were analysed. The Camino transducer, which is reported to have a frequency bandwidth of $33 \mathrm{~Hz}$, was taken as a
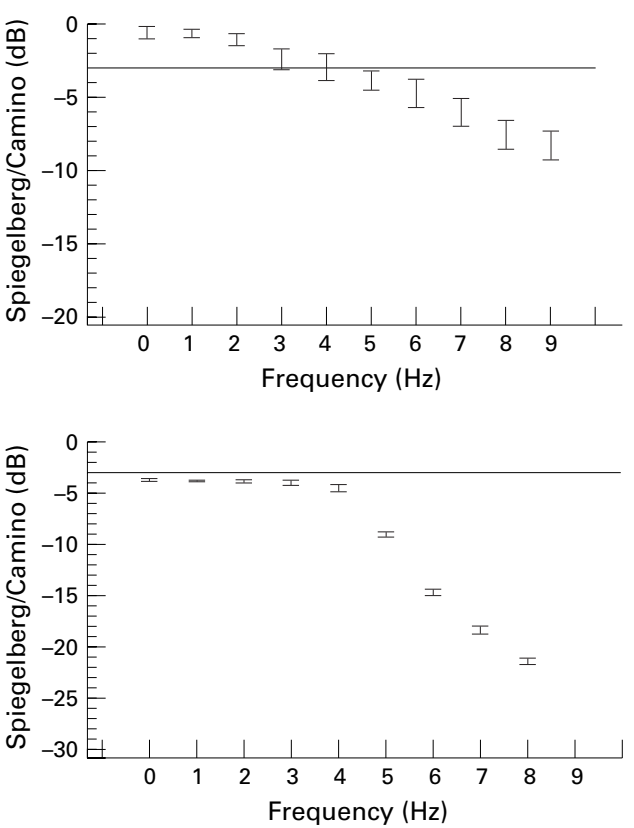

Figure 5 (A) Frequency response of the Spiegelberg transducer (v Camino) at a mean pressure level of $0 \mathrm{~mm}$ H. Horizontal line indicates $-3 \mathrm{~dB}$ level. (B) Frequency response of the Spiegelberg transducer ( $v$ Camino) at a mean pressure level of $50 \mathrm{~mm} \mathrm{Hg}$.

reference transducer. The measurements were conducted at two static pressure levels: $10 \mathrm{~mm}$ $\mathrm{Hg}$ and $50 \mathrm{~mm} \mathrm{Hg}$.

At $10 \mathrm{~mm} \mathrm{Hg}$ frequency the Spiegelberg transducer showed $3 \mathrm{~dB}$ bandwidth from 0 to 4 $\mathrm{Hz}$ (fig 5A). At $50 \mathrm{~mm} \mathrm{Hg}$ the $-3 \mathrm{~dB}$ cut off frequency was formally shown at $0 \mathrm{~Hz}$ (fig $5 \mathrm{~B}$ ). But the $-3 \mathrm{~dB}$ cut off frequency relative to the value measured at $0 \mathrm{~Hz}$ was at $5 \mathrm{~Hz}$

The frequency response of the Siegelberg monitor depended on the mean pressure. The Spiegelberg transducer cannot be described in terms of a linear system. For low pressures, however, a $-3 \mathrm{~dB}$ cut off frequency is surprisingly high $(4 \mathrm{~Hz})$.

ACCURACY OF MEASUREMENT OF PULSE PRESSURE A sine wave pulse pressure of amplitude around $5 \mathrm{~mm} \mathrm{Hg}$ and fundamental frequency of $1.5 \mathrm{~Hz}$ was produced as in the frequency response testing. Constant pressure was changed gradually by increasing the infusion rate from 0 to $3 \mathrm{ml} / \mathrm{min}$ in steps of $0.05 \mathrm{ml} / \mathrm{min}$ every minute (stopcock 3 open fig 1 ). As in the frequency investigations, only relative differences in readings were analysed. The test revealed that the amplitude recorded by the Spiegelberg transducer is dependent upon the mean pressure: the higher the pressure, the lower the amplitude (fig 6).

\section{RECORDING OF PULSE PRESSURE}

The pattern of recorded pressure was similar in the Camino and the Spiegelberg monitors. A constant delay of $0.1 \mathrm{~s}$ was recorded by the Spiegelberg monitor (fig 7). This delay seemed to be independent of the amplitude of the waveform and its frequency. 


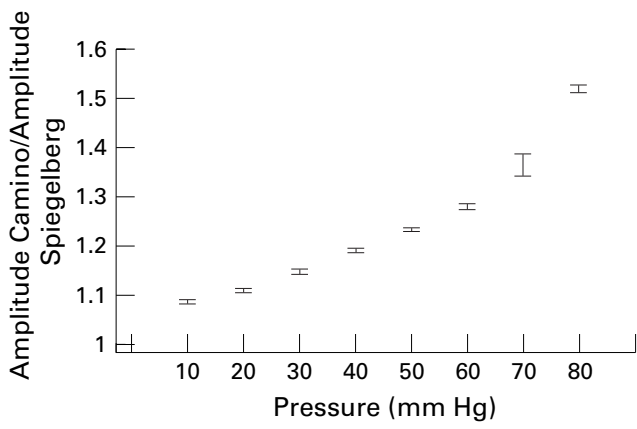

Figure 6 Ratio of the amplitude of pulse wave (frequency 90 evolutions / $\mathrm{min}$ ) measured by the Camino/Spiegelberg monitor ratio, versus static pressure level. The Spiegelberg monitor underestimates amplitude when mean pressure increases.

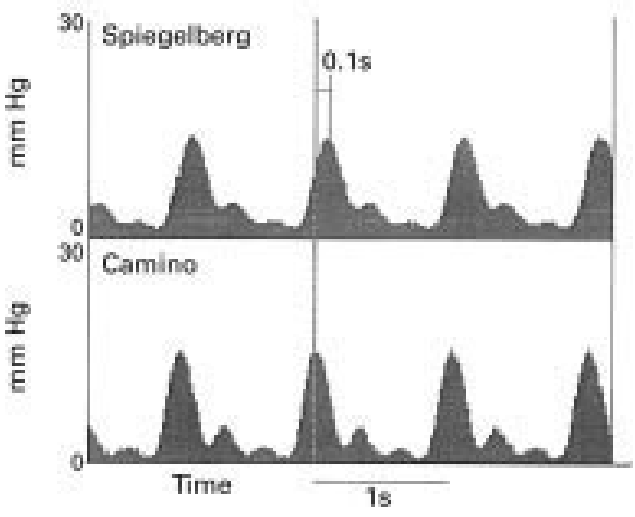

Figure 7 Simulated ICP pulse waveform recorded by the Spiegelberg (upper graph) and Camino monitor (bottom graph).

\section{Discussion}

The Spiegelberg brain pressure monitor seems to be a good alternative to expensive ICP microtransducers for measurement of static pressure. $^{2}$ (Costs of disposable transducers are Spiegelberg £100, Camino £225. Prices for monitoring units are comparable: Spiegelberg $£ 4000$, Camino £4500.)

For measurement of the ICP pulsatile pattern, the accuracy is limited by low frequency response ( $4 \mathrm{~Hz}$ at a low ICP) and non-linear distortion, as amplitude underestimation increases when the mean pressure increases. This is the main drawback of the use of the Spiegelberg transducer in the wide bandwidth pulse analysis of ICP. ${ }^{4}$ Simple pulse waveform detection limited to the first harmonic ${ }^{5}$ seems to be still possible. Although distortion of the amplitude reading is modest (around 10\% underreading per $20 \mathrm{~mm} \mathrm{Hg}$ of static pressure), calculation of the correlation coefficient between changes in the amplitude and mean ICP level ${ }^{56}$ may be biased.

Analysis of the response of ICP to changes in arterial pressure, ${ }^{7}$ phase shift, ${ }^{8}$ or correlation coefficient ${ }^{6}$ between slow waves of ICP and arterial pressure, methods recently documented to disclose the state of mechanism actively regulating cerebral arterial blood volume, ${ }^{9}$ seems to be fully possible.

It is still not clear whether the non-linear distortion of the measurement of pulse pattern may influence the accuracy of continuous estimation of the pressure-volume index, ${ }^{10}$ a method which has been recently integrated into the Spiegelberg monitor. Further laboratory evaluation is needed to avoid unnecessary criticism.

\section{Conclusion}

At present we can recommend the Spiegelberg brain monitor for the continuous recording of mean ICP in clinical practice, including analysis of slow waves.

We thank A Spiegelberg for providing the brain pressure monitor and transducers for testing, and to Mrs Jo Copeman and Dr Andreas Raabe for reviewing the final text. Funds for the research were not provided by any of the manufacturers and the authors have no commercial interest in these devices. Measurements were performed in the UK Shunt Evaluation Laboratory funded by the Department of Health Medical Devices Agency.

1 Hermann HD, Loeffler WH. Spiegelberg brain-pressure monitor. Neurosurgery 1993;33:1111-2.

2 Schwarz M, Matuschka H, Meznik A. Die SpiedelbergSonde zur epiduralen ICP- registrung. Unfallchirurg 1992; 95:113-7

3 Czosnyka M, Czosnyka Z, Pickard JD. Laboratory testing of three intracranial pressure microtransducers: technical report. Neurosurgery 1996;38:219-24.

4 Robertson C, Narayan R, Contant C, et al. Clinical experience with continuous monitor of intracranial compliance. $\mathcal{7}$ Neurosurg 1989;71:673-80.

5 Czosnyka M, Guazzo E, Whitehouse H, Smielewski P, Czosnyka Z, Kirkpatrick P, et al. Significance of intracranial pressure waveform analysis after head injury. Acta Neurochir (Wien) 1996;138:531-42.

6 Czosnyka M, Kirkpatrick PJ, Pickard JD. Multimodal monitoring and assessment of cerebral haemodynamic reserve after severe head injury. Cerebrovasc Brain Metab Rev 1996; 8:273-95.

7 Lang EW, Chesnut RM. Intracranial pressure and cerebral perfusion pressure after severe head injury. New Horiz perfusion press

8 Steimeier R, Bauhuf C, Hubner U, Bauer RD, Fahlbusch R, Laumer R, Bondar I. Slow rhytmic oscillations of blood pressure, intracranial pressure, microcirculation and cerebral oxygenation. Dynamic interrelation and time course in humans. Stroke 1996;27:2236-43.

9 Rosner MJ, Becker DP. Origins and evaluation of plateau waves. Experimental observations and theoretical model. 7 Neurosurg 1984;60:312-24.

10 Piper I, Spiegelberg Am Bernardo A, Mascia L, Whittle I, Miller JD. Automated compliance measurement in brain injured patients; a new method [abstract]. The J Douglas Miller Memorial Meeting Edinburgh, 1996.

\section{Manufacturer's comment}

We appreciate Dr Czosnyka's work and we fully agree with the results of his laboratory tests. However, we find the last paragraph of the discussion misleading. The recently developed method to continuously monitor the compliance and the PVI uses a small amount of air which is repeatedly injected into the balloon at the tip of the catheter. The small pressure response is determined using a second pressure transducer, either external or on the catheter tip. The measure does not rely on the pressure measurement via the air filled balloon. The non-linear distortion does not influence the compliance measurement. We look forward to Dr Czosnyka's assessment of the compliance measurement system, once the system becomes available

A SPIEGELBERG

President, Spiegelberg ( $\mathrm{GmbH}$ and $\mathrm{Co}$ ) KG Tempowerking 4, D-21079, Hamburg, Germany 